\title{
The differences between patients with panic disorder and healthy controls in psychophysiological stress profile
}

This article was published in the following Dove Press journal:

Neuropsychiatric Disease and Treatment

\author{
Antonia Kotianova ${ }^{1,2}$ \\ Michal Kotian ${ }^{2}$ \\ Milos Slepecky ${ }^{1,2}$ \\ Michaela Chupacova ${ }^{2}$ \\ Jan Prasko 1,3 \\ Ingrid Tonhajzerova ${ }^{4,5}$
}

'Department of Psychology Sciences, Faculty of Social Science and Health Care, Constantine the Philosopher University in Nitra, Nitra, Slovak Republic; ${ }^{2}$ Psychagogia, Garbiarska, Liptovsky Mikulas, Slovak Republic; ${ }^{3}$ Department of Psychiatry, Faculty of Medicine and Dentistry, University Palacky Olomouc, University Hospital, Olomouc, Czech Republic; ${ }^{4}$ Department of Physiology, Jessenius Faculty of Medicine in Martin, Comenius University in Bratislava, Martin, Slovak Republic; ${ }^{5}$ Biomedical Center Martin, Jessenius Faculty of Medicine in Martin, Comenius University in Bratislava, Martin, Slovak Republic
Correspondence: Milos Slepecky Department of Psychology Sciences, Faculty of Social Science and Health Care, Constantine the Philosopher University in Nitra, Kraskova I, 94974 Nitra, Slovak Republic

Tel +42I 903500887

Email milos.slepecky@gmail.com
Background: Alarming somatic symptoms, in particular, cardiovascular symptoms, are the characteristic feature of panic attacks. Increased cardiac mortality and morbidity have been found in these patients. Power spectral analysis of electrocardiogram R-R intervals is known to be a particularly successful tool in the detection of autonomic instabilities in various clinical disorders. Our study aimed to compare patients with panic disorder and healthy controls in heart rate variation (HRV) parameters (very-low-frequency [VLF], low-frequency [LF], and high-frequency $[\mathrm{HF}]$ band components of R-R interval) in baseline and during the response to the mental task.

Subjects and methods: We assessed psychophysiological variables in 33 patients with panic disorder (10 men, 23 women; mean age 35.9 \pm 10.7 years) and 33 age- and gender-matched healthy controls (10 men, 23 women; mean age 35.8 \pm 12.1 years). Patients were treatment naïve. Heart rate, blood pressure, muscle tension, and HRV in basal conditions and after the psychological task were assessed. Power spectrum was computed for VLF (0.003-0.04 Hz), LF (0.04-0.15 Hz), and HF $(0.15-0.40 \mathrm{~Hz})$ bands using fast Fourier transformation.

Results: In the baseline period, the VLF band was significantly lower in panic disorder group compared to controls $(p<0.005)$. In the period of mental task, the $\mathrm{LF} / \mathrm{HF}$ ratio was significantly higher in panic disorder patients compared to controls $(p<0.05)$. No significant differences were found in the remaining parameters. There was a significant difference in $\Delta \mathrm{HF}$ and $\Delta \mathrm{LF} / \mathrm{HF}$ ratio between patients and controls, with $\Delta$ increasing in patients and decreasing in controls.

Conclusion: These findings revealed that patients suffering from panic disorder were characterized by relative sympathetic dominance (reactivity) in response to mental stress compared with healthy controls.

Keywords: panic disorder, heart rate variability, pulse, blood pressure, muscle tension, psychological task

\section{Introduction}

Patients with panic disorder are characterized by higher baseline heart rate (HR) and periods of tachycardia which coincide with panic symptoms. ${ }^{1,2}$ Increased cardiac mortality and morbidity have been suggested in these patients. ${ }^{3}$ Klein et al $^{4}$ studied resting electrocardiographic recordings in panic disorder and controls using power spectrum analysis of the beat-to-beat interval of HR. Patients had decreased heart rate variability (HRV) and substantial reduction in the high-frequency (HF) peaks of the power spectrum densities. Yeragani et $\mathrm{al}^{5}$ found that patients with panic disorder showed decreased SD and average consecutive difference of the $\mathrm{R}-\mathrm{R}$ intervals, especially in standing posture. In a later study, they investigated power spectral analysis in patients with panic disorder 
and found that panic disorder patients had a significantly lower power in the very-low-frequency (VLF) band and a higher relative power in the low-frequency (LF) band in standing posture. They also found that patients with panic disorder had an exaggerated cardiac vagal withdrawal during lactate infusions compared with normal controls. ${ }^{5}$ Klein et al ${ }^{4}$ described a higher resting LF/HF in patients with panic disorder compared with normal controls. Slaap et $\mathrm{al}^{6}$ reported that panic disorder patients, who did not respond to medication, were described at baseline with a higher HR. Five-minute HRV recording was obtained in medication-free panic patients before 12-week, open-label treatment with mirtazapine and was analyzed using spectral analysis. The LF power and the total spectrum were significantly higher in mirtazapine responders than in nonresponders. These findings suggest that no responders to short-term mirtazapine treatment are characterized at baseline by a lower output of the autonomic nervous system (ANS) at the beginning of the treatment. Lavoie et $\mathrm{al}^{7}$ evaluated HRV in coronary artery disease patients with and without panic disorder by $48 \mathrm{~h}$ electrocardiographic monitoring. Power spectral analysis of HRV indicated that coronary artery disease patients with panic disorder exhibited significantly lower LF/ HF ratios, which, according to the authors, may reflect lower sympathetic modulation, compared with non-panic disorder patients. Total power in panic disorder patients was made up of a significantly lower proportion of VLF power and a significantly higher proportion of HF power, compared to non-panic disorder patients. Baker et al, ${ }^{8}$ in a double-blind, randomized, 4-week study with clonazepam or placebo, recorded HRV from 24-hour Holter sample acquisitions at baseline and the end of the study and performed standard sleep measures. None of the HRV measures correlated with response; but compared with placebo, clonazepam led to a decrease in all the time and frequency domains of HRV. Slaap et $\mathrm{al}^{9}$ used spectral analysis of HRV in drug-free panic disorder patients, obsessive compulsive disorder (OCD) patients, and normal controls. The results showed that neither OCD patients nor panic disorder patients were characterized by a reduced HRV, as compared to normal controls. Prasko et al, ${ }^{10}$ in a small study with 19 panic patients and 18 healthy volunteers, demonstrated a lower autonomic activity in patients with panic disorder in comparison with controls and a tendency to increase this autonomic power during the treatment. Tonhajzerova et $\mathrm{al}^{11}$ found that HRV is lower in adolescent patients with major depressive disorder (MDD), especially in the HF band component. The next study supported these findings, in which the authors compared a group of 20 adolescent girls with an MDD to 20 healthy controls and found significantly reduced HRV complexity in the supine rest position and after posture change, especially in the standing position. ${ }^{12}$ Slepecky et $\mathrm{al}^{13}$ found that in healthy persons, a higher total score of life events was significantly negatively correlated with total HF power. Diveky et $\mathrm{al}^{14}$ found highly significant differences between panic disorder patients and healthy control group in all components of power spectral analysis during an orthostatic test in the second and third VLF components (standing and supine positions) and in HF components of a second position (standing) of the experiment. The authors had found negative correlations between the level of dissociation and some parameters of ANS.

Our previous studies revealed that HRV represents a sensitive noninvasive approach to the objective assessment of sympathovagal balance in mental stress. ${ }^{15,16}$ In our past work on panic disorder, we investigated the HRV during an orthostatic change in patients and controls. ${ }^{10}$ The differences between patients and controls were significant. Our question that emerged after the first study was if mental stress also could influence the HRV parameters in these patients. Patients with the panic disorder typically reported that panic attack occurred without any trigger (out of the blue). Uncued panic attacks are also in diagnostic criteria of International Classification of Diseases version 10 (ICD-10) and in correspondence with clinical experiences. ${ }^{17,18}$ They showed a high level of dissociation too. ${ }^{19,20}$ Nevertheless, during psychotherapy, they typically start to recognize several triggers of panic attacks, which are connected with stressful inner experiences and thoughts. ${ }^{21,22}$

\section{The study aim}

The purpose of the investigation is to compare autonomic reactivity in response to mental stress in patients with panic disorder using short-term HRV analysis.

\section{Hypotheses}

The hypotheses of the study are as follows:

1. There will be impaired sympathovagal balance in patients with panic disorder compared to healthy controls.

2. The sympathovagal balance will be different during a mental task in panic disorder patients compared to healthy controls.

3. The difference in parasympathetic reactivity during mental task will be lower in patients than in controls.

\section{Subjects and methods Subjects}

Outpatients from the Department of Psychiatry and Psychology, Psychagogia, Liptovsky Mikulas, were recruited for 
the study. The diagnosis of panic disorder was established based on a clinical interview conducted by two experienced clinicians. Inclusion criteria are as follows: 1) diagnosis based on ICD- $10^{23}$ research criteria for panic disorder or panic disorder with agoraphobia, 2) had been without any medication at least 1 month, 3) age 18-60 years, and 4) provided written informed consent. Exclusion criteria are as follows: 1) lifetime prevalence of MDD, 2) high risk of suicidality, 3) lifetime prevalence of organic psychiatric disorder, 4) lifetime prevalence of psychotic disorder, 5) lifetime dependence on alcohol or other substances, 6) severe physical illness, 7) pregnancy or lactation, and 8) hypertension, diabetes, endocrinopathy.

Demographic data, including age, sex, the age of onset of the disorder, and duration of disorder, were obtained in the interview.

The control group was recruited from healthy subjects without any psychopathological or somatic complaints and not using any medication currently. ${ }^{13}$ They were also required to not have used any psychopharmacological medication in their lifetime. The HRV measures were strictly the same as in the patient's group.

The physiological measurements are as follows:

1. HR - It is defined as heart beats per minute.

2. HRV - The differences in the ANS activity, indexed by HRV, were measured by the analytic system ProComp Infiniti using the power spectral analysis of the beat-tobeat time series. HRV was assessed 5 minutes at rest and 5 minutes during a mental arithmetic task. The following data were taken and processed by ProComp Infiniti hardware and software:

- Power spectrum was calculated by a fast Fourier transformation for VLF $(0.0033-0.04 \mathrm{~Hz}), \mathrm{LF}$ (0.04-0.15 Hz), and HF (0.15-0.40 Hz) powers. ${ }^{24}$

- $\mathrm{SDRR}$ - SD of R-R intervals provides information about the total HRV. This measurement shows how much variability exists during a given period. It is the SD of interbeat interval values calculated over a minute. Since the SD is a representation of how spread out the interbeat interval values are, higher SDRR values represent greater variability.

- HRV total was the sum of all measured frequencies (VLF+LF+HF).

\section{Evaluated parameters Evaluated HRV parameters}

The primary outcome measures were $\mathrm{LF} / \mathrm{HF}$ ratio and $\mathrm{HF}$. The secondary outcome measures were HR, LF, SDRR, total HRV power, and the difference between measurements during the mental test and basal conditions in all previous parameters.

\section{Mental task}

Mental arithmetic, repeating subtracting 7 from 1081, was chosen as a performance stress. The counting was done mentally without saying results; the final result only was compared with the correct one. The procedure has been selected to eliminate artifact mostly from speaking.

\section{Ethical issues}

The investigation was performed in agreement with the Guideline for Good Clinical Practice and the latest version of the Helsinki Declaration. ${ }^{25}$ The local ethical committee of the Faculty of Social Science and Health Care, Constantine the Philosopher University in Nitra, approved this study. Written informed consent was obtained from the participants after the procedures were fully explained.

\section{Statistical analysis}

Statistics were calculated by using statistical software SPSS 24.0 for Windows and Prism (GraphPad Prism version 5.0). Demographic, physiological, and psychological data were analyzed using column statistics. The applied statistical procedures were descriptive statistics for the demographic data, mean scores, and a character of data distribution. The Shapiro-Wilk test determined normality of distribution of the variables. The Levene's test for equality of variances was used for testing their homogeneity. According to their significance, the results from SPSS rows were selected. Differences between scores or measures were computed by independent $t$-tests or Mann-Whitney tests in alternative subgroups of data according to the type of data distribution. Pearson or Spearman correlations analyzed the relationships between factors. Differences were considered to be significant when $p$-values were $<0.05$.

\section{Results}

\section{Sample characteristics}

Thirty-three patients with panic disorder (23 women) with a mean age of $35.9 \pm 10.7$ years were included in the study. All patients were without any medication. Thirty-three healthy controls ( 23 women) with a mean age of $35.8 \pm 12.1$ years were included in the study. There was no statistical difference between patients and controls in their mean age and gender distribution. 
Table I The autonomic parameters at baseline period and during mental task

\begin{tabular}{|c|c|c|c|}
\hline Measure & Controls $(n=33)$ & Panic disorder $(n=33)$ & Statistics \\
\hline Age, years & $35.91 \pm 10.68$ & $35.82 \pm 12.11$ & Unpaired $t$-test: $t=0.0323, d f=64 ; n s$ \\
\hline $\mathrm{HR}, \mathrm{bpm}$ & $70.20 \pm 15.83$ & $77.01 \pm 10.78$ & Mann-Whitney test: $M W U=396 ; n s(p=0.058)$ \\
\hline SDRR, interbeat intervals/min & $56.61 \pm 26.65$ & $45.75 \pm 19.14$ & Unpaired $t$-test: $t=1.862, d f=6 \mathrm{I} ; \mathrm{ns}(p=0.067)$ \\
\hline VLF, $\mathrm{Hz}$ & $175.50 \pm 318.10$ & $60.48 \pm 52.09$ & Mann-Whitney test: MW U=25I; $p<0.005$ \\
\hline LF, $\mathrm{Hz}$ & $190.20 \pm 174.10$ & $166.80 \pm 235.10$ & Mann-Whitney test: $M W U=400 ; n s$ \\
\hline $\mathrm{HF}, \mathrm{Hz}$ & $160.80 \pm 179.00$ & $137.10 \pm 228.8$ & Mann-Whitney test: $M W U=4 \mid 8$; ns \\
\hline LF/HF ratio & $1.96 \pm 1.93$ & $1.91 \pm 2.28$ & Mann-Whitney test: $M W U=402.5 ;$ ns \\
\hline Respiration rate, rpm & $14.10 \pm 3.74$ & $14.44 \pm 3.78$ & Unpaired $t$-test: $t=0.369 \mathrm{I}, \mathrm{df}=64 ; \mathrm{ns}$ \\
\hline $\mathrm{HRV}$ total power, $\mathrm{ms}^{2} / \mathrm{Hz}$ & $526.50 \pm 563.20$ & $383.00 \pm 457.50$ & Unpaired $t$-test: $t=1.090, d f=59 ; \mathrm{ns}$ \\
\hline MT_HR, mean bpm & $79.68 \pm 14.56$ & $83.04 \pm 11.22$ & Unpaired $t$-test: $t=1.052, d f=64 ;$ ns \\
\hline MT_SDRR, interbeat intervals/min & $59.13 \pm 21.29$ & $56.85 \pm 31.54$ & Mann-Whitney test: $M W U=459$; ns \\
\hline MT_VLF, Hz & $1 \mathrm{II} .20 \pm 120.90$ & $71.73 \pm 55.18$ & Unpaired $t$-test: $t=1.639, d f=6 \mathrm{I} ; \mathrm{ns}$ \\
\hline MT_LF, $\mathrm{Hz}$ & $122.80 \pm 108.30$ & $147.10 \pm \mid 34.20$ & Unpaired $t$-test: $t=0.7936, d f=6 \mathrm{I} ; \mathrm{ns}$ \\
\hline MT_HF, Hz & $|24.50 \pm| 28.40$ & $153.70 \pm 263.10$ & Mann-Whitney test: MW U=407; ns \\
\hline MT_LF/HF ratio & $1.31 \pm 0.90$ & $2.14 \pm 2.05$ & Unpaired $t$-test: $t=2.108, d f=6 \mathrm{I} ; p<0.05$ \\
\hline MT_resp rate, rpm & $|5.79 \pm 2.2|$ & $15.62 \pm 4.22$ & Unpaired $t$-test: $t=0.1985, d f=64 ; \mathrm{ns}$ \\
\hline MT_HRV total power, ms & $358.50 \pm 256.10$ & $372.50 \pm 411.80$ & Unpaired $t$-test: $t=0.1639, d f=61$; ns \\
\hline
\end{tabular}

Abbreviations: $d f$, degrees of freedom; HF, high frequency; HR, heart rate; HRV, heart rate variability; LF, low frequency; MT, mental test; ns, not significant; MW, MannWhitney; SDRR, SD of R-R intervals; VLF, very low frequency.

\section{The activity of the ANS}

In the baseline period, the VLF band was significantly lower in panic disorder (PD) group compared to controls $(p<0.005)$. In the period of mental task, the $\mathrm{LF} / \mathrm{HF}$ ratio was significantly higher in PD patients compared to controls $(p<0.05)$. No significant differences were found in the remaining parameters (Table 1).

There was a significant difference in $\Delta \mathrm{HF}$ and $\Delta \mathrm{LF} / \mathrm{HF}$ ratio between patients and controls, with $\Delta$ increasing in patients and decreasing in controls (Table 2).

\section{Discussion}

Our findings suggest that the resting cardiac activity is characterized by alterations in sympathovagal balance resulting in a relative increase of sympathetic activity and a reduction of parasympathetic modulation in panic patients. In contrast, the response to mental stress is characterized by increased parasympathetic modulation in panic disorder compared to a decrease of the cardiac-linked parasympathetic activity (vagal withdrawal) in controls. These findings revealed impaired cardiac regulatory autonomic mechanisms in response to mental stress, indicating potential inflexibility and rigidity in panic disorder.

Traditionally, it has been postulated that increased noradrenergic activity in panic disorder results in increased activity of the sympathetic nervous system. ${ }^{26,27}$ Chalmers et al, ${ }^{28}$ in their meta-analysis, concluded that anxiety disorders are characterized by reduced HRV. The effect size was small to moderate. Nagpal et al, ${ }^{29}$ in their meta-analysis of HRV, found that in posttraumatic stress disorder patients, the LF/ HF ratio was significantly higher. In contrast, several recent studies revealed no significant effect of panic disorder on HRV. ${ }^{30}$ Furthermore, Wang et $\mathrm{al}^{31}$ concluded that the mean change in sympathovagal index LF/HF ratio from baseline to

Table 2 The physiological parameters indicating reactivity to stress

\begin{tabular}{|c|c|c|c|}
\hline Measure & Controls $(n=33)$ & Panic disorder $(n=33)$ & Statistics \\
\hline$\Delta \mathrm{HR}$ & $9.48 \pm 12.64$ & $6.04 \pm 5.92$ & Unpaired $t$-test: $t=1.417, d f=64$; ns \\
\hline$\triangle \mathrm{SDRR}$ & $1.52 \pm 24.92$ & $9.23 \pm 27.33$ & Unpaired $t$-test: $t=|| 68,. d f=6 \mid$; ns \\
\hline$\Delta \mathrm{VLF}$ & $-60.14 \pm 225.70$ & $12.87 \pm 53.86$ & Mann-Whitney test: MW U=367; ns \\
\hline$\Delta \mathrm{LF}$ & $-67.96 \pm 163.30$ & $-26.27 \pm 193.90$ & Unpaired $t$-test: $t=0.9029, \mathrm{df}=58 ; \mathrm{ns}$ \\
\hline$\Delta \mathrm{HF}$ & $-48.12 \pm 140.10$ & $16.60 \pm 160.70$ & Unpaired $t$-test: $t=2.220, d f=62 ; p<0.05$ \\
\hline$\Delta \mathrm{LF} / \mathrm{HF}$ ratio & $-0.63 \pm 1.79$ & $0.22 \pm 2.91$ & Mann-Whitney test: $M W U=3 \mid 5 ; p<0.05$ \\
\hline$\Delta \mathrm{HRV}$ total power & $-176.20 \pm 420.00$ & $-10.52 \pm 273.80$ & Unpaired $t$-test: $t=0.5033, d f=64 ; \mathrm{ns}(p=0.074)$ \\
\hline
\end{tabular}

Abbreviations: $\Delta$, difference between the basal and mental test conditions; $d f$, degrees of freedom; HF, high frequency; HR, heart rate; HRV, heart rate variability; LF, low frequency; ns, not significant; SDRR, SD of R-R intervals; VLF, very low frequency. 
the active stimulus was significantly lower in emotion regulation group compared to the non-regulation group of the panic disorder patients. These authors concluded that brief emotion acceptance training could decrease aversive stimulus-induced sympathetic hyperactivity in patients with PD. ${ }^{31}$

Our results show that under basal conditions, the autonomic vegetative activity measured by HRV in PDs patients differs from healthy controls only with borderline higher HR and SDRR, significantly lower is only mean VLF in patients in comparison with controls, probably reflecting decreased baroreceptor activity. After the mental test, panic disorder patients showed a significant increase in $\mathrm{LF} / \mathrm{HF}$ ratio, that is, they showed augmented reactivity on a mental task, which was not apparent in controls.

\section{Our hypotheses were mostly confirmed}

The first hypothesis, "there will be impaired sympathovagal balance in patients with panic disorder in comparison with healthy controls", was confirmed only marginally by borderline differences between mean HR, SDRR, and a significant difference in VLF.

The second hypothesis, "the sympathovagal balance will be different during a mental task in panic disorder patients compared to healthy controls", was confirmed fully. Patients reaction to mental task was higher than the response of healthy controls. Some researchers consider the LF/HF ratio (ratio of low- to high-frequency spectra) as an index of sympathovagal balance. ${ }^{32}$ For example, Castaldo et al, ${ }^{33}$ in their meta-analysis, showed that $\mathrm{LF} / \mathrm{HF}$ ratio was significantly increased during stress, and HF power was significantly decreased. They assumed that there are sympathetic activation and parasympathetic withdrawal during stress reaction, which reflect in the HRV changes. We suggest that our results demonstrate a more exaggerated reaction to mental stress indexed by LF/HF in panic disorder patients; however, the change in cardiac parasympathetically mediated response was diminished in panic disorder, resulting in less ability to adapt in response to mental stress. The neurovisceral integration model highlights a role for the prefrontal cortex in an inhibitory function via a vagally mediated pathway indexed by HF-HRV ${ }^{34,35}$ Moreover, the polyvagal theory emphasized a role for the myelinated vagus in social, behavioral states by inhibiting cardiac sympathetic activity associated with the increased vagal activity. ${ }^{36}$ In other words, when the environment is perceived as safe, vagal outflow increases, promoting adaptability, flexibility, homeostasis, and social behavior. Notably, impairment of these neural processes may play a role in the development of the anxiety disorders including panic disorder. ${ }^{28}$ In this context, the abnormal cardiac autonomic "pattern" in response to mental stress found in our panic disorder group might reflect complex impaired neurocardiac and emotional integrity.

The third hypothesis, "difference in parasympathetic reactivity during mental task will be lower in the patient than in controls", was confirmed. The increase in HF reactivity indicates less flexibility of the ANS in reaction to exposure to mental task, which was not reported in previous panic disorder studies. ${ }^{28}$ The study results show that the patient with panic disorder demonstrates an increased sympathetic reactivity during mental stress in comparison with healthy controls.

From the pathophysiological point of view, the ANS and its regulation could have an essential role in the pathophysiology of panic disorder. Increased reactivity of sympathetically mediated cardiac activity during mental stress could be the critical factor that contributes to acute panic attacks.

This study confirms that patients with panic disorder may overreact to stress-related stimuli associated with mental performance by the sympathovagal response. For the therapy, it implies 1) the importance to explore and change the thought and emotional processes that precede and accompany panic attack and 2) the training of sympathovagal regulation by exercises and breathing or biofeedback procedure.

From the assessment point of view, a recent study indicated that panic disorder could be a risk factor for cardiovascular diseases, raising morbidity and mortality in panic disorder, suggesting an association between them. ${ }^{37}$ In this context, the question regarding the sensitive and noninvasive assessment of cardiovagal dysregulation as a risk factor for cardiovascular complications in panic disorder is still unclear. HRV could be one candidate for such an approach.

\section{Limitations}

This study has several limitations. First, the physiological relevance of VLF, LF, and HF bands and their relation to sympathetic and parasympathetic nervous systems are not entirely clear; therefore, cautions statements should be made at this point about the physiological significance of our findings. Second, the number of patients and controls was relatively small.

\section{Conclusion}

This study revealed relative sympathetic dominance (reactivity) indexed by HRV analysis in response to mental stress in PD patients compared with healthy controls, which could be associated with a higher risk of cardiovascular complications in panic disorder. 


\section{Acknowledgments}

This paper was supported by the research grant APVV-150502: Psychological, psychophysiological, and anthropometric correlates of cardiovascular diseases, VEGA 1/0044/18, the project "Biomedical Center Martin" (BioMed) cofinanced by EU sources (ITMS 26220220187).

\section{Disclosure}

The authors report no conflicts of interest in this work.

\section{References}

1. Freedman RR, Ianni P, Ettedgui E, Puthezhath N. Ambulatory monitoring of panic disorder. Arch Gen Psychiatry. 1985;42(3):244-248.

2. Liebowitz MR, Gorman JM, Fyer AJ, et al. Lactate provocation of panic attacks. II. Biochemical and physiological findings. Arch Gen Psychiatry. 1985;42(7):709-719.

3. Katerndahl DA. The association between panic disorder and coronary artery disease among primary care patients presenting with chest pain: an updated literature review. Prim Care Companion J Clin Psychiatry. 2008;10(4):276-285.

4. Klein E, Cnaani E, Harel T, Braun S, Ben-Haim SA. Altered heart rate variability in panic disorder patients. Biol Psychiatry. 1995;37(1): 18-24.

5. Yeragani VK, Srinivasan K, Balon R, Ramesh C, Berchou R. Lactate sensitivity and cardiac cholinergic function in panic disorder. Am J Psychiatry. 1994;151(8):1226-1228.

6. Slaap BR, Boshuisen ML, van Roon AM, den Boer JA. Heart rate variability as predictor of nonresponse to mirtazapine in panic disorder: a preliminary study. Int Clin Psychopharmacol. 2002;17(2):69-74.

7. Lavoie KL, Fleet RP, Laurin C, Arsenault A, Miller SB, Bacon SL. Heart rate variability in coronary artery disease patients with and without panic disorder. Psychiatry Res. 2004;128(3):289-299.

8. Baker B, Khaykin Y, Devins G, Dorian P, Shapiro C, Newman D. Correlates of therapeutic response in panic disorder presenting with palpitations: heart rate variability, sleep, and placebo effect. Can J Psychiatry. 2003;48(6):381-387.

9. Slaap BR, Nielen MM, Bohuisen ML, van Roon AM, den Boer JA. Five-minute recording of heart rate variability in obsessive-compulsive disorder, panic disorder and healthy volunteers. J Affect Disord. 2004;78(2):141-148.

10. Prasko J, Latalova K, Diveky T, et al. Panic disorder, autonomic nervous system and dissociation - changes during therapy. Neuro Endocrinol Lett. 2011;32(5):641-651.

11. Tonhajzerova I, Ondrejka I, Javorka M, et al. Respiratory sinus arrhythmia is reduced in adolescent major depressive disorder. Eur $J$ Med Res. 2009;14(Suppl 4):280-283.

12. Tonhajzerova I, Ondrejka I, Javorka K, Turianikova Z, Farsky I, Javorka M. Cardiac autonomic regulation is impaired in girls with major depression. Prog Neuropsychopharmacol Biol Psychiatry. 2010;34(4):613-618.

13. Slepecky M, Kotianova A, Prasko J, et al. Which psychological, psychophysiological, and anthropometric factors are connected with life events, depression, and quality of life in patients with cardiovascular disease. Neuropsychiatr Dis Treat. 2017;13:2093-2104.

14. Diveky T, Prasko J, Kamaradova D, et al. Comparison of heart rate variability in patients with panic disorder during cognitive behavioral therapy program. Psychiatr Danub. 2013;25(1):62-67.

15. Visnovcova Z, Mestanik M, Javorka M, et al. Complexity and time asymmetry of heart rate variability are altered in acute mental stress. Physiol Meas. 2014;35(7):1319-1334.

16. Mestanik M, Mestanikova A, Visnovcova Z, Calkovska A, Tonhajzerova I. Cardiovascular sympathetic arousal in response to different mental stressors. Physiol Res. 2015;64(Suppl 5):S585-S594.
17. Kircanski K, Craske MG, Epstein AM, Wittchen HU. Subtypes of panic attacks: a critical review of the empirical literature. Depress Anxiety. 2009;26(10):878-887.

18. Pfaltz MC, Michael T, Meyer AH, Wilhelm FH. Reexperiencing symptoms, dissociation, and avoidance behaviors in the daily life of patients with PTSD and patients with panic disorder with agoraphobia. J Trauma Stress. 2013;26(4):443-450.

19. Pastucha P, Praško J, Grambal A, et al. Panic disorder and dissociation comparison with healthy controls. Neuro Endocrinol Lett. 2009; 30(6):774-778.

20. Ural C, Belli H, Akbudak M, Tabo A. Childhood traumatic experiences, dissociative symptoms, and dissociative disorder comorbidity among patients with panic disorder: a preliminary study. J Trauma Dissociation. 2015;16(4):463-475.

21. Ising M, Höhne N, Siebertz A, Parchmann AM, Erhardt A, Keck M. Stress response regulation in panic disorder. Curr Pharm Des. 2012; 18(35):5675-5684.

22. Otto MW, Tolin DF, Nations KR, et al. Five sessions and counting: considering ultra-brief treatment for panic disorder. Depress Anxiety. 2012;29(6):465-470

23. World Health Organization. The ICD-10 Classification of Mental and Behavioral Disorders: Diagnostic Criteria for Research. Geneva, Switzerland: World Health Organization; 1993.

24. Malik M. Heart rate variability. Standards of measurement, physiological interpretation, and clinical use. Task Force of the European Society of Cardiology Cardiology and the North American Society of Pacing and Electrophysiology. Eur Heart J. 1997;17(1):354-381.

25. EMEA, 2002. Available from: http://www.ema.europa.eu/pdfs/human/ ich/013595en.pdf. Accessed March 3, 2009.

26. Ko GN, Elsworth JD, Roth RH, Rifkin BG, Leigh H, Redmond DE Jr. Panic-induced elevation of plasma MHPG levels in phobic-anxious patients. Effects of clonidine and imipramine. Arch Gen Psychiatry. 1983;40(4):425-430.

27. Villacres EC, Hollifield M, Katon WJ, Wilkinson CW, Veith RC. Sympathetic nervous system activation in panic disorder. Psychiatry Res. 1987;21(4):313-321.

28. Chalmers JA, Quintana DS, Abbott MJ, Kemp AH. Anxiety disorders are associated with reduced heart rate variability: a meta-analysis. Front Psychiatry. 2014;5:80.

29. Nagpal ML, Gleichaur K, Ginsberg JP. Meta-analysis of heart rate variability as a psychophysiological indicator of posttraumatic stress disorder. J Traum Treat. 2013;182.

30. Petrowski K, Wichmann S, Siepmann T, Wintermann GB, Bornstein SR, Siepmann M. Effects of mental stress induction on heart rate variability in patients with panic disorder. Appl Psychophysiol Biofeedback. 2017;42(2):85-94.

31. Wang SM, Lee HK, Kweon YS, et al. Effect of emotion regulation training in patients with panic disorder: evidenced by heart rate variability measures. Gen Hosp Psychiatry. 2016;40:68-73.

32. Bansal D, Khan M, Salhan AK. A computer-based wireless system for online acquisition, monitoring and digital processing of ECG waveforms. Comput Biol Med. 2009;39(4):361-367.

33. Castaldo R, Xu W, Melillo P, Pecchia L, Santamaria L, James C. Detection of mental stress due to oral academic examination via ultrashort-term HRV analysis. Conf Proc IEEE Eng Med Biol Soc. 2016; 2016:3805-3808

34. Thayer JF, Lane RD. A model of neurovisceral integration in emotion regulation and dysregulation. J Affect Disord. 2000;61(3):201-216.

35. Friedman BH. Autonomic flexibility-neurovisceral integration model of anxiety and cardiac vagal tone. Biol Psychol. 2007;74(2):185-199.

36. Porges SW. The Polyvagal Theory: Neurophysiological Foundations of Emotions, Attachment, Communication and Self-Regulation. New York, NY: W. W. Norton \& Company; 2011.

37. Machado S, Sancassiani F, Paes F, Rocha N, Murillo-Rodriguez E, Nardi AE. Panic disorder and cardiovascular diseases: an overview. Int Rev Psychiatry. 2017;29(5):436-444 


\section{Publish your work in this journal}

Neuropsychiatric Disease and Treatment is an international, peerreviewed journal of clinical therapeutics and pharmacology focusing on concise rapid reporting of clinical or pre-clinical studies on a range of neuropsychiatric and neurological disorders. This journal is indexed on PubMed Central, the 'PsycINFO' database and CAS, and is the official journal of The International Neuropsychiatric Association (INA). The manuscript management system is completely online and includes a very quick and fair peer-review system, which is all easy to use. Visit http://www.dovepress.com/testimonials.php to read real quotes from published authors.

Submit your manuscript here: http://www.dovepress.com/neuropsychiatric-disease-and-treatment-journal 